\title{
Pengembangan Purwarupa Node Multi Sensor Pemantau Parameter Cuaca Berbasis Mikrokontroler
}

\author{
Handy Indra Regain Moseya*
}

aJurusan Fisika, FMIPA, Unsrat, Manado

\section{K A T A K U N C I}

Node Sensor

Sensor Tekanan

Sensor Cahaya

Sensor Hujan

Sensor Suhu

Mikrokontroler

\begin{abstract}
A B S T R A K
Telah dilakukan penelitian untuk membuat purwarupa node multi sensor yang dapat digunakan sebagai pemantau parameter cuaca. Informasi kondisi cuaca secara local sekarang ini dirasakan cukup penting untuk diketahui secepatnya untuk mendukung bidang ilmu lain yang berkaitan dengannya. Dalam penelitian ini telah berhasil dibuat node multi sensor dengan menggunakan beberapa sensor sekaligus yaitu sensor tekanan, sensor cahaya, sensor hujan, sensor suhu dan mikrokontroler sebagai pengendali. Data yang didapat dari pembacaan node kemudian dibandingkan dengan data dari aplikasi pemantau cuaca daring. Dari hasil perbandingan data, didapatkan margin error pembacaan node sensor dengan nilai yang sangat baik dengan rentang nilai dari 3,17\% - 0,001\%.

A B S T R A C T

Research had been done to develop a multi sensor which can be uses as weather parameter monitoring. Nowadays, knowing the information of the weather condition locally as quickly as possible are considered very important to support other areas. In this research has been successfully built a multi sensor node in which pressure sensor, light sensor, raindrop sensor, temperature sensor are attached to a microcontroller to control the behavior of the sensors. Data collected by sensor node then compared with the data read by two online application for weather. Data comparison shows good degree of accuracy with margin of error value of $3,17 \%-0,001 \%$ in interval.
\end{abstract}

KE Y W OR D S

Sensor Node

Pressure Sensor

Light Sensor

Rain Drop Sensor

Temperature Sensor

Microcontroller
TERSEDIAONLINE

01 Februari 2017

\section{Pendahuluan}

Sejalan dengan perkembangan teknologi, pengumpulan data secara akurat sangat dibutuhkan. Salah satunya dalam bidang klimatologi. Menurut Harisuryo (2015) dan Setiono (2016) informasi parameter cuaca seperti suhu, kelembaban, tekanan udara dan hujan pada lokasi dan waktu tertentu harus segera diketahui secara cepat untuk mendukung bidang ilmu lain yang terkait dengannya.

Badan Meteorologi, Klimatologi dan Geofisika (BMKG) merupakan badan pemerintah yang bertugas mengamati perkembangan iklim, cuaca dan potensi gempa bumi di seluruh kepulauan yang berada di Indonesia. Sekarang ini BMKG memiliki sekitar 173 stasiun cuaca yang tersebar di seluruh indonesia. Pada laman daring resmi BMKG, tingkat akurasi, presisi dan informasi terkini belum dapat memberikan informasi secara real-time. Informasi cuaca daerah setempat belum dapat diinformasikan secara luas. Pemantauan kondisi cuaca pada lingkungan daerah setempat saat ini dirasakan cukup penting diketahui. Beberapa bidang seperti transportasi maupun industri agrobisnis sangat membutuhkan informasi kondisi cuaca setempat (Setiono, 2016).

Dari beberapa referensi yang telah dibaca, beberapa peneliti seperti Yawut, et al (2011), Ardianto, et al (2012), Saefullah, et al (2015), Siswanto, et al (2015), Hakim, et al (2015), Krisnamurthi, et al (2015), Rosidi, et al (2015), dan Saini, et al (2016) telah mengembangkan purwarupa node sensor yang mengombinasikan sensor-sensor seperti sensor suhu, kelembaban, intensitas cahaya, curah hujan dan tekanan udara. Namun tidak merupakan kombinasi dari semua sensor yang disebutkan.

Dalam penelitian ini dikembangkan sebuah node multi-sensor berbasis mikrokontroler dan beberapa 
sensor yang merupakan kombinasi dari sensor suhu, kelembaban, intensitas cahaya, curah hujan dan tekanan udara. Purwarupa node multi-sensor ini diharapkan dapat dijadikan purwarupa yang dapat dikembangkan menjadi stasiun cuaca local yang dapat merekam dan menampilkan kondisi cuaca secara realtime pada suatu lokasi yang memerlukannya.

\section{Material dan Metode Material}

Material yang digunakan dalam penelitian ini yakni: - $\quad$ Arduino UNO R3 Dev Kit

Board mikrokontroler berdasarkan pada chip ATMega328. Board ini mempunyai 14 pin I/O (6 diantaranya dapat digunakan sebagai output PWM), 6 input analog, sebuah osilator kristal $16 \mathrm{MHz}$, koneksi USB, powerjack, ICSP header dan tombol Reset. Koneksi dengan komputer dapat menggunakan USB. Catu daya dapat menggunakan baterai atau adaptor. Bentuk Fisik Arduino UNO R3 ini dapat dilihat pada Gambar 1.

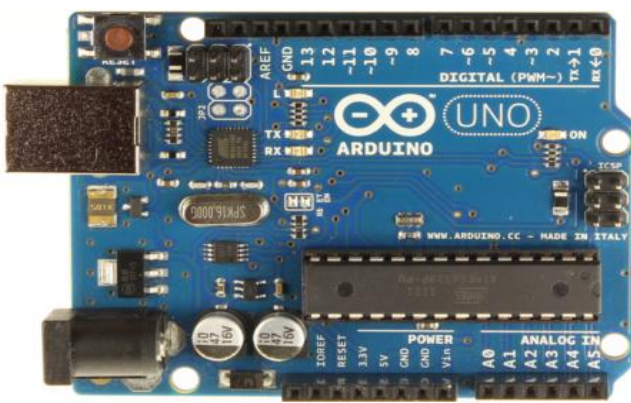

Gambar 1. Board Arduino UNO R3

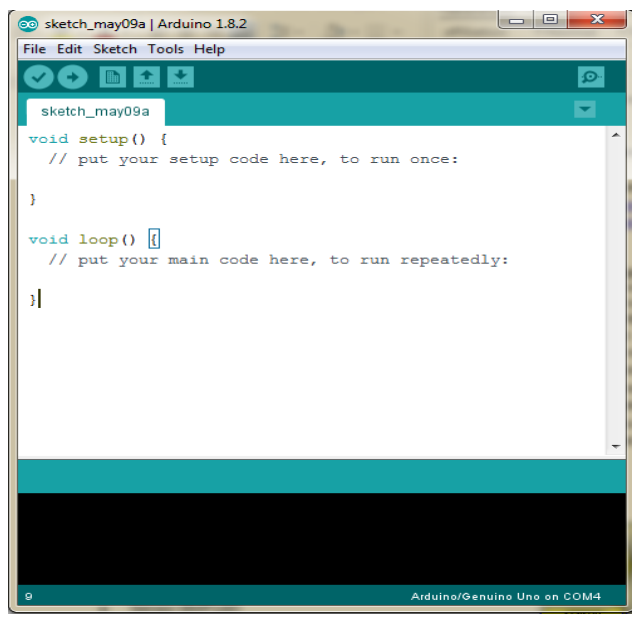

Gambar 2. Arduino IDE

Untuk memrogram modul ini dapat menggunakan perangkat lunak Arduino IDE (Integrated Development Environment) (Gambar 2). Perangkat lunak ini dapat diunduh secara gratis pada laman resminya (http://arduino.cc) .

\section{- $\quad$ Sensor DHT22}

DHT22 adalah sensor yang dapat mengukur suhu dan kelembaban udara. DHT22 memiliki keandalan tinggi dan stabilitas jangka panjang yang sangat baik. Bentuk Fisik sensor ini dapat dilihat pada Gambar 3.

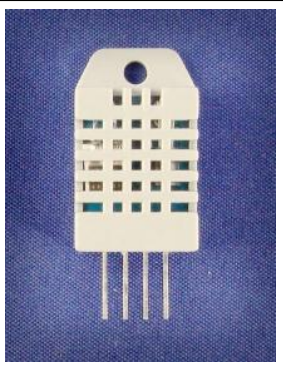

Gambar 3. Sensor Kelembaban dan Suhu DHT22

Fitur yang dimiliki sensor ini dapat diunduh dari laman https://www.sparkfun.com/datasheets/Sensors/Tempe rature/DHT22.pdf

- Sensor BMP180

Sensor ini dapat mengukur tekanan udara menggunakan barometer digital. Tingkat akurasi sensor ini mencapai satu meter. Bentuk Fisik sensor ini dapat dilihat pada Gambar 4.

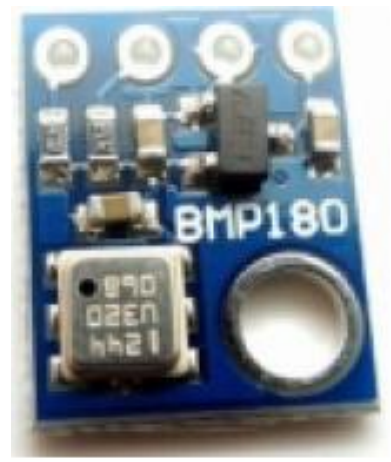

Gambar 4. BMP180

Fitur yang dimiliki sensor ini dapat diunduh dari laman https://cdn-shop.adafruit.com/datasheets/BSTBMP180-DS000-09.pdf

- Sensor hujan

Sensor ini bekerja berdasarkan prinsip kapasitif untuk mendeteksi tetesan air. Bentuk Fisik sensor ini dapat dilihat pada Gambar 5.

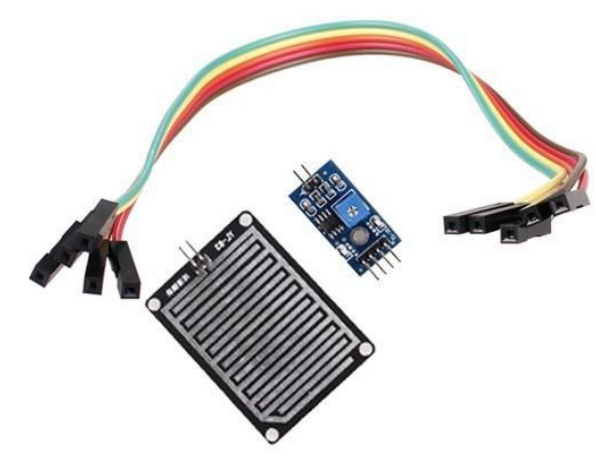

Gambar 5. Sensor Hujan 
Fitur yang dimiliki sensor ini dapat diunduh dari laman https://www.openhacks.com/uploadsproductos/rain_s ensor module.pdf

\section{- Sensor cahaya}

Sensor ini sering disebut sensor LDR (Light Dependent Resistor). LDR merupakan komponen dengan karakteristik resistor yang memiliki kepekaan terhadap cahaya. Bentuk Fisik sensor ini dapat dilihat pada Gambar 6.

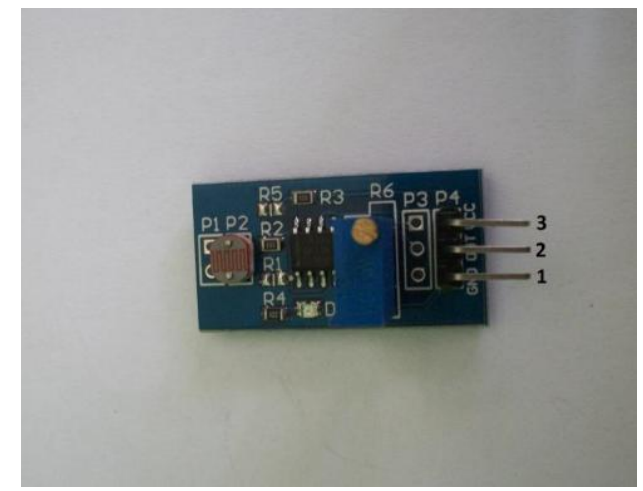

Gambar 6. Sensor cahaya

Fitur yang dimiliki sensor ini dapat diunduh dari laman http://www.energiazero.org/arduino_sensori/photosens itive_sensor_module.pdf

\section{Metode}

Metode pengembangan sistem yang digunakan dalam penelitian ini yaitu desain perangkat keras dan desain perangkat lunak.

\section{Desain Perangkat Keras}

Desain perangkat keras meliputi pengujian masing masing sensor, merangkai modul-modul sensor ke pengendali mikrokontroler dan menampilkan hasil pembacaan sensor melalui komunikasi serial. Parameter-parameter cuaca yang dibaca kemudian ditampilkan melalui Display. Diagram blok node multisensor dapat dilihat pada gambar 7 .

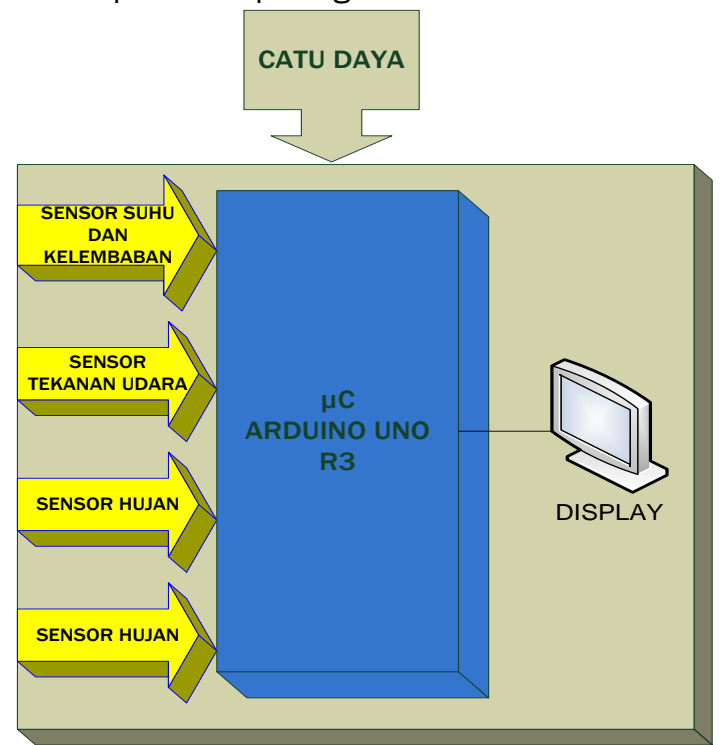

Gambar 7. Diagram Blok Purwarupa Rangkaian Node Multi-sensor
2. Desain Perangkat Lunak

Desain perangkat lunak meliputi pemrograman masingmasing sensor yaitu: deklarasi variabel, inisiasi program, pembacaan sensor-sensor, dan menampilkan hasil bacaan sensor melalui komunikasi serial. Flowchart sistem perangkat lunak dapat dilihat pada gambar 8 .

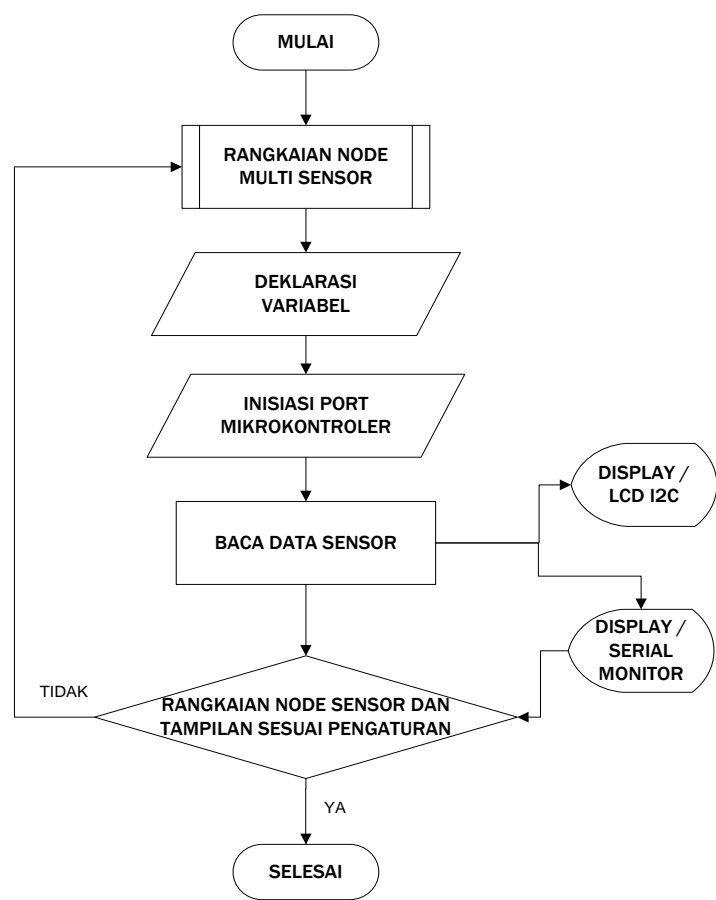

Gambar 8. Flowchat Sistem

\section{Hasil dan Pembahasan}

Setelah Rangkaian node multi sensor yang telah dibangun (Gambar 9) telah terhubung dengan komputer kemudian dlakukan pengujian pada node untuk mengetahui apakah sensor dapat bekerja sesuai pengaturan.

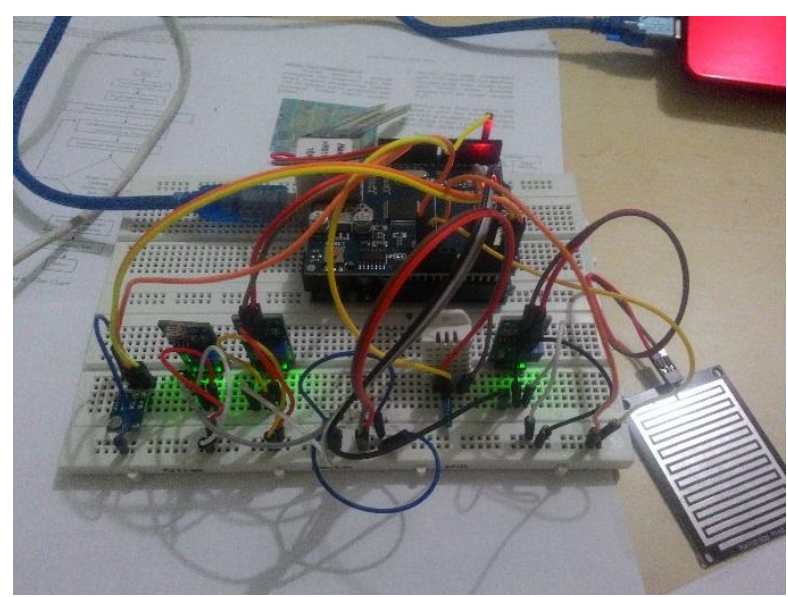

Gambar 9. Foto Node Multi Sensor Yang dibangun

Hasil bacaan sensor ditampilkan melalui monitor Laptop menggunakan komunikasi serial (Gambar 10). 


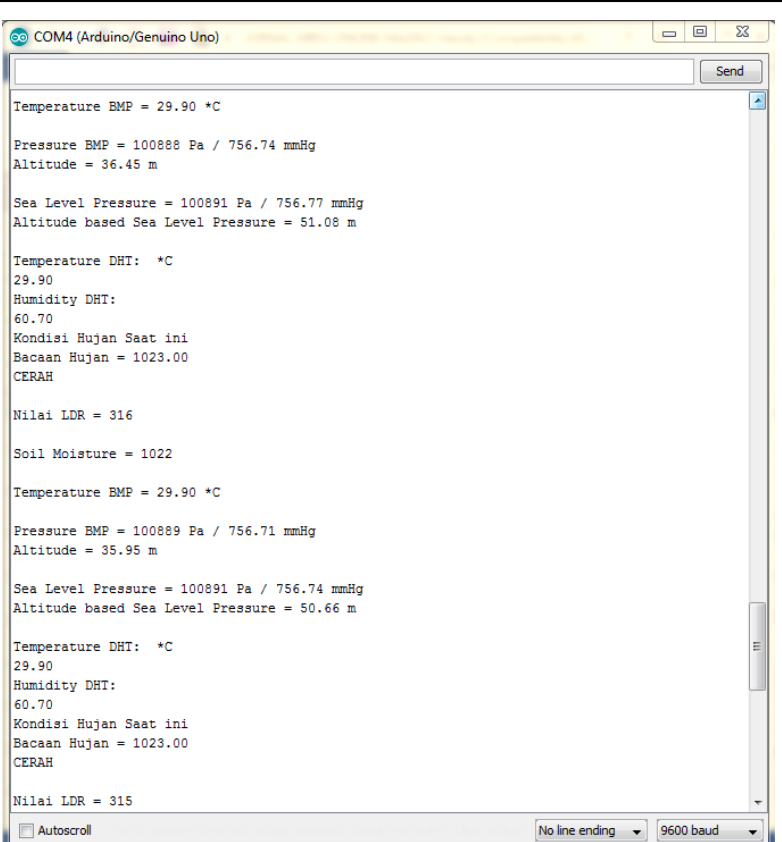

Gambar 10. Tampilan Serial Monitor Arduino IDE

Hasil yang didapatkan dari alat yang dibuat yakni berupa data-data pembacaan sensor menunjukan bahwa sensor-sensor dapat melakukan pembacaan parameter-parameter cuaca dengan baik. Parameterparameter tersebut yaitu data suhu, kelembaban, tekanan, curah hujan. Data hasil pembacaan node kemudian dibandingkan dengan beberapa aplikasi cuaca daring yaitu dari www.openweathermap.org dan aplikasi android yakni AccuWeather pada telepon pintar bermerk ASUS Zenphone 5. Berikut disajikan data perbandingannya.

Tabel 1. Hasil Pengukuran Suhu

\begin{tabular}{|c|c|c|c|c|}
\hline No. & $\begin{array}{c}\text { Jam } \\
(\text { p.m })\end{array}$ & $\begin{array}{c}\text { Node } \\
\text { Multi } \\
\text { Sensor } \\
\left({ }^{\circ} \mathrm{C}\right)\end{array}$ & $\begin{array}{c}\text { Open- } \\
\text { weather- } \\
\text { map.org } \\
\left({ }^{\circ} \mathrm{C}\right)\end{array}$ & $\begin{array}{c}\text { Accu- } \\
\text { weather } \\
\left({ }^{\circ} \mathrm{C}\right)\end{array}$ \\
\hline 1 & $1: 00$ & 30,6 & 32 & 33 \\
\hline 2 & $1: 30$ & 30,8 & 32 & 33 \\
\hline 3 & $2: 00$ & 31 & 32 & 32 \\
\hline 4 & $2: 30$ & 30,5 & 32 & 32 \\
\hline 5 & $3: 00$ & 30,5 & 32 & 31 \\
\hline 6 & $3: 30$ & 29,5 & 29 & 29 \\
\hline & Rata-rata & 30,5 & 31,5 & 31,6 \\
\hline
\end{tabular}

Dari tabel pengukuran di atas didapatkan:

- Margin error untuk pengukuran oleh Node Multi Sensor terhadap www.openweathermap.org yaitu:

$$
100 \%-\left(\frac{30,5}{31,5}\right) x 100 \%=3,17 \%
$$

- margin error untuk pengukuran oleh Node Multi Sensor terhadap aplikasi Accuweather yaitu:

$$
100 \%-\left(\frac{30,5}{31,5}\right) \times 100 \%=3,48 \%
$$

Margin error yang cukup besar ini dikarenakan data yang diambil oleh node sensor adalah data yang secara langsung dibaca node sensor di lokasi FMIPA Universitas Sam Ratulangi lokal, sementara data pembanding merupakan data rata-rata suhu secara umum di kota Manado.

Tabel 2. Hasil Pengukuran Tekanan

\begin{tabular}{|c|c|c|c|c|}
\hline No. & $\begin{array}{c}\text { Jam } \\
(\mathrm{p} . \mathrm{m})\end{array}$ & $\begin{array}{c}\text { Node Multi } \\
\text { Sensor } \\
(\mathrm{Pa})\end{array}$ & $\begin{array}{c}\text { Open- } \\
\text { weather- } \\
\text { map.org } \\
(\mathrm{Pa})\end{array}$ & $\begin{array}{c}\text { Accu- } \\
\text { weather } \\
(\mathrm{Pa})\end{array}$ \\
\hline 1 & $1: 00$ & 100891 & 100900 & 100900 \\
\hline 2 & $1: 30$ & 100890 & 100900 & 100900 \\
\hline 3 & $2: 00$ & 100885 & 100900 & 100900 \\
\hline 4 & $2: 30$ & 100885 & 100900 & 100900 \\
\hline 5 & $3: 00$ & 100870 & 100900 & 100900 \\
\hline 6 & $3: 30$ & 100890 & 100900 & 100900 \\
\hline & $\begin{array}{c}\text { Rata- } \\
\text { rata }\end{array}$ & 100885.2 & 100900 & 100900 \\
\hline
\end{tabular}

Dari tabel pengukuran di atas didapatkan:

- margin error untuk pengukuran oleh Node Multi Sensor terhadap www.openweathermap.org yaitu:

$$
100 \%-\left(\frac{100885,2}{100900}\right) \times 100 \%=0,14 \%
$$

- margin error untuk pengukuran oleh Node Multi Sensor terhadap aplikasi Accuweather yaitu:

$$
100 \%-\left(\frac{100885,2}{100900}\right) \times 100 \%=0,14 \%
$$

Tabel 3. Hasil Pengukuran Kelembaban

\begin{tabular}{|c|c|c|c|c|}
\hline No. & $\begin{array}{c}\text { Jam } \\
\text { (p.m) }\end{array}$ & $\begin{array}{c}\text { Node } \\
\text { Multi } \\
\text { Sensor } \\
(\%)\end{array}$ & $\begin{array}{c}\text { Open- } \\
\text { weather- } \\
\text { map.org } \\
(\%)\end{array}$ & $\begin{array}{c}\text { Accu- } \\
\text { weather } \\
(\%)\end{array}$ \\
\hline 1 & $1: 00$ & 63.7 & 62 & 62 \\
\hline 2 & $1: 30$ & 64 & 64 & 63 \\
\hline 3 & $2: 00$ & 66.4 & 66 & 66 \\
\hline 4 & $2: 30$ & 66.6 & 66 & 66 \\
\hline 5 & $3: 00$ & 67 & 70 & 66 \\
\hline 6 & $3: 30$ & 64 & 70 & 69 \\
\hline & Rata-rata & 65,283 & 66,333 & 65,333 \\
\hline
\end{tabular}

Dari tabel pengukuran di atas didapatkan:

- margin error untuk pengukuran oleh Node Multi Sensor terhadap www.openweathermap.org yaitu:

$$
100 \%-\left(\frac{65,283}{66,333}\right) \times 100 \%=0,015 \%
$$

- margin error untuk pengukuran oleh Node Multi Sensor terhadap aplikasi Accuweather yaitu:

$$
100 \%-\left(\frac{65,283}{65,333}\right) \times 100 \%=0,001 \%
$$


Untuk data dari sensor hujan tidak sajikan dalam tabel dikarenakan disaat pengambilan data tidak terjadi hujan. Demikian juga dengan data hujan dari kedua pembanding di atas. Sedangkan untuk data dari sensor LDR, tidak dibandingkan karena tidak ditemukan data pada pembanding daring.

\section{Kesimpulan}

Dari hasil pengujian dan analisa yang telah dilakukan pada Node Multi Sensor untuk mengukur parameter-parameter cuaca, dapat diambil beberapa kesimpulan sebagai berikut:

1. Node Multi Sensor yang telah dibangun telah bekerja sesuai pengaturan yang diinginkan.

2. Margin error pengukuran suhu Node Multi Sensor terhadap data openweather sebesar 3,17\%.

3. Margin error pengukuran suhu Node Multi Sensor terhadap data accuweather sebesar 3,48 \%.

4. Margin error pengukuran tekanan Node Multi Sensor terhadap data openweather sebesar 0,14\%.

5. Margin error pengukuran tekanan Node Multi Sensor terhadap data accuweather sebesar 0,14\%.

6. Margin error pengukuran kelembaban Node Multi Sensor terhadap data openweather sebesar 0,015\%.

7. Margin error pengukuran suhu Node Multi Sensor terhadap data accuweather sebesar 0,001\%.

8. Penelitian terhadap pengembangan node multi sensor ini dapat dilakukan dengan menambahkan beberapa sensor pengukur parameter cuaca lainnya, datalogging, dan alat lainnya untuk memublikasikan data bacaanya secara daring.

\section{Daftar Pustaka}

Ardianto, L., Sumiharto, R. 2012. Implementasi Jaringan Sensor Nirkabel Berbasis XBee Studi Kasus Pemantauan Suhu dan Kelembaban. IJEIS. 2:2 (2012): 119-130.

Hakim, A., Hulu, C. 2015. Rancang Bangun Alat Pengontrol Suhu Dan Lampu Otomatis Menggunakan Arduino Uno R3 Sebagai System Pengendali. Einstein 3 (1) (2015): 48-56.

Harisuryo, R., Sumardi., Setiyono, B. System Pengukuran Data Suhu, Kelembaban, Dan Tekanan Udara Dengan Telemetri Berbasis Frekuensi Radio. Transient 4 (3) (2015): 652659.

Krisnamurthi, K., Tahap, S., Kothari, L., Prakash, A. 2015. Arduino Based Weather Monitoring System. IJERGS 3 (2) (2015): 452-458

Rosidi, D.F., Harianto., Susanto, P. 2015. Pemantauan Suhu dan Kelembaban Secara Otomatis Yang Terintegrasi Datalogging Berbasis Arduino. JAVA Journal of Electrical and Electronics Engineering 13 (2) (2015): 25-30.

Saefullah, A., Sunarya, A., Fakrizal, D. 2014. Prototype Weather Station Berbasis Arduino Yun. 8 (2) (2015): 57-65.

Saini, H., Thakur, A., Ahuja, S., Sabharwal, N. 2016. Arduino Based Automatic Wireless Weather Station with Remote Graphical Application and Alerts. $3^{\text {rd }}$ International Conference on Signal Processing and Integrated Networks (SPIN) (2016): 605-609.

Setiono, B., Sumardi., Harisuryo, R. 2015. Measurement System of Temperature, Humidity and Air Pressure over $433 \mathrm{MHz}$ Radio Frequency. $2^{\text {nd }}$ Int. Conference on Information Technology, Computer and Electrical Engineering (ICITACEE) (2015): 438-441.

Siswanto, D., Winardi, S. 2015. Jemuran Pakaian Otomatis Menggunakan Sensor Hujan dan Sensor LDR Berbasis Arduino UNO. e-JURNAL NARODROID 1 (2) (2015): 66-73.

Yawut, C., Kilaso, S. A Wireless Sensor Network for Weather and Disaster Alarm System. IPCSIT 6 (2011): 155-159. 